\title{
Clinical effects of overwintered-stressed Chondrus Crispus and non-overwintered-stressed Chondrus crispus dietary supplementations
}

\author{
Beniamino Palmieri', Maria Vadalà ${ }^{2}$, Carmen Laurino ${ }^{3}$ \\ ${ }^{1}$ Professor, Department of General Surgery and Surgical Specialities, University of Modena and Reggio Emilia. \\ Largo del Pozzo 71, 41124 Modena (MO). Second Opinion Medical Network, Modena (MO), Italy, 2,3Medical Doctor, \\ Department of General Surgery and Surgical Specialities, University of Modena and Reggio Emilia. Largo del Pozzo \\ 71, 41124 Modena (MO). Second Opinion Medical Network, Modena (MO), Italy
}

\section{A B S T R A C T}

Background: Chondrus crispus is red seaweed widespread in the northern Atlantic coasts due to the high proteins, burden it is quite helpful supplement for some symptoms such as fatigue, asthenia, and weakness and for supporting skeletal muscles in sports athletes. Aims and Objectives: This retrospective observational "not inferiority" study investigates and compares the clinical effects of overwintered-stressed Chondrus Crispus and non-overwinteredstressed Chondrus crispus dietary supplementations for the treatment of musculoskeletal and articular symptomatology related diseases. Materials and Methods: Eighty patients were retrospectively reviewed through the Second Opinion Medical Network. Patients were prescribed 3 capsules/day after the main meals for 3 weeks of overwintered-stressed Chondrus Crispus or non-overwintered stressed Chondrus crispus dietary supplementations. Quality of life (QOL) assessment was evaluated by the Short Form-36 (SF-36) health survey questionnaire before starting the treatment and after the third week. Benefits declared by patients were also reported after the treatment in addition to some subjective observations related to the symptomatology and to the health status. Results: Fifty patients were treated with overwintered-stressed Chondrus Crispus and 30 patients were treated with the non-overwintered-stressed Chondrus crispus dietary supplementation. The general benefit of treatment with overwintered-stressed Chondrus Crispus was 76\%, while that obtained with non-overwintered-stressed Chondrus crispus was $33.3 \%(\mathrm{P}<0.01)$. Results of SF-36 general health status after the treatment demonstrated that 37 patients $(74 \%)$ and 11 patients $(36.7 \%)$ felt better than before in the overwintered-stressed Chondrus Crispus group and non-overwintered-stressed Chondrus crispus group, respectively $(\mathrm{P}<0.01)$. A great improvement of subjective exhaustion, fatigue, pain, digestive, and peristalsis disturbances symptoms, in addition to mood and concentration amelioration that would be a consequence of symptomatology regression, was also observed. Conclusions: This retrospective observational comparative study evidences that overwinteredstressed Chondrus Crispus improved musculoskeletal and articular symptomatology related diseases better than non-overwintered-stressed Chondrus crispus.

Key words: Chondrus crispus; Energy; fatigue; Musculoskeletal symptoms; Articular symptoms; Overwintered; Cold; L-citrullynin-L-arginine

\section{INTRODUCTION}

The red seaweed Chondrus crispus (Rhodophyta) is widely distributed in the northern Atlantic. ${ }^{1}$ As an economically important seaweed species in the Atlantic Canada region, Chondrus crispus is also cultivated on land in Nova Scotia, Canada. ${ }^{1}$

In addition to high content of total proteins, oligopeptides and pigments, this alga is rich in the water-soluble 
polysaccharide carrageenan (approximately $50-65 \%$ on a basis of dry weight). ${ }^{2,3}$ Carrageenan is widely used in the food industry as a thickener, stabilizer and emulsifier.

Thanks to the high content of total proteins among these seaweeds, Chondrus crispus is in the folk medicine, reputed as effective supplement for some symptoms such as fatigue, asthenia, and weakness and for supporting skeletal muscles in sports athletes. ${ }^{4}$

Physiologically, the food content in amino acids is the substrate of biosynthesis of structural and functional proteins in the body. These digested amino acids can be used for oxidative phosphorylation and gluconeogenesis ${ }^{5,6}$ as well as the facilitation of numerous physiological functions including acting as precursors for the biosynthesis of neurotransmitters, hormones, phosphoglycerols, glycolipids and nucleic acids. ${ }^{7,8}$

It has been estimated that the skeletal muscles in the human body are $40-60 \%$ of body mass and thus represent the major bulk of the body's protein. 'The body does not has specific protein stores, but when it is not possible to obtain sufficient protein via ingestion during exercise, illness or trauma, it breaks down proteins to amino acids via the process of proteolysis where the non-myofibrillar proteins display a high turnover rate to meet demands. ${ }^{10}$ The amino acids released from this turnover of protein can enter the blood circulation for metabolism as required and can be lost in sweat and urine. ${ }^{5,6}$

An increased amino acids recruitment would be seen during illness and recovery from trauma ${ }^{11}$ as also in sarcopenia ${ }^{12}$ an in patients with critical illness or other muscle wasting illness. ${ }^{13}$ Increased losses of amino acids were observed in cancer patients affecting by fatigue during and following radiation therapy and chemotherapy, involving amino acid homeostasis. ${ }^{11}$ Significantly, depleted amino acid levels have also been associated with long-term fatigue leading often to a frank nitrogen imbalance. ${ }^{14}$

This retrospective observational comparative study investigates and compares the clinical effects of overwinteredstressed Chondrus Crispus* and non-overwintered-stressed Chondrus crispus dietary supplementations for the treatment of musculoskeletal and articular symptomatology related diseases.

\section{MATERIALS AND METHODS}

Patients. We reviewed medical records (electronic or paperbased) of 80 patients that had appealed to our "Second Opinion Medical Network", (Modena, Italy), between January and April 2018, because of musculoskeletal and articular symptomatology (asthenia, fatigue, articular, musculoskeletal, rheumatic and post-traumatic pain, digestive and peristalsis disturbances and migraine). Patients were aged over 40 years and were affected at least 6 months by different clinical conditions (cancer, infections, sarcopenia, colitis, rheumatologic, traumatic, musculoskeletal, articular, autoimmune and genetic diseases) with an attested related symptomatology and diagnosis. The Second Opinion Medical Network is a consultation referral web and Medical Office System recruiting a wide panel of real-time available specialists, to whom any patient affected by any disease or syndrome and not satisfied with the diagnosis or therapy, can apply for an individual clinical audit. ${ }^{15}$ Due to the doctorpatient communication gap, most of the patients usually wander around the medical websites looking for proper answers to their health problems. However, this search often becomes compulsive and obsessive and is frequently ambiguous and frustrating. Palmieri et al, ${ }^{16}$ describe this borderline or even pathological behaviour as the "Web Babel Syndrome" - a psychological imbalance affecting young and elderly patients, especially those with multiple synchronous diseases who receive from their caregivers heterogeneous and misleading information or advice, including confused, contradictory statements and prescriptions. ${ }^{17}$ To deal with this problem, the Second Opinion Network aims to be a useful "problem-solving" support revisiting each diagnostic and therapeutic step and properly re-addressing tailored treatments and prognoses, as well as preventing unnecessary investigational procedures and unhelpful and expensive medical and surgical interventions. ${ }^{15}$

All patients used pharmacological treatments, dietary supplementation, surgery, manual and electro - medical physiotherapy especially for the management of pain and strain with only partial benefit from them. However, these strategies produces light, moderate or severe side effects (e.g., hypersensitivity reactions, sensation of pressure or constriction, flushing to face and in the thoracic region, asthenia, myalgia, drowsiness, insomnia, restlessness, vertigo, gastrointestinal symptoms, skin rashes, nausea, vomiting, etc.), and frequent drug interactions and contraindications. Dietary supplementation included herbal products and nutraceutical supplementations, while electro-medical physiotherapy was based on laser therapy, iontophoresis, magneto therapy, electrostimulation, etc.

In our clinical practice, we washed out previous treatments for a period of 2 weeks, and then the dietary supplementations were administered.

The selected patients were informed, via individual interview, and informed consent previously approved by the Local Institutional Review Board under the Helsinki Declaration. 
Study design and dietary supplementations. We run a retrospective observational "not inferiority" study for 3 weeks duration. At the start up the patients were prescribed 3 capsules/day after the main meals of overwintered-stressed Chondrus Crispus of either non-overwintered stressed Chondrus crispus dietary supplementations. Each capsule contains $500 \mathrm{mg}$ of $100 \%$ powder of the overwintered-stressed red seaweed or $500 \mathrm{mg}$ of $100 \%$ powder of the non-overwintered-stressed red seaweed. overwintered-stressed Chondrus Crispus is naturally enriched in a dipeptide, the L-citrullynin-L-arginine $(2.8 \%-4 \%)$, with antioxidant and energizing properties, compared to the non-overwintered-stressed Chondrus crispus $(0.2 \%)$. The cultivation method of overwintered-stressed Chondrus Crispus consists to expose to overwintered conditions the Chondrus crispus with increased production of amino acids and others peptides (European Patent 1652435B1). Energizing and antioxidant peptides contained in both the dietary supplementations are summarized in Table 1.

The first clinical examination consisted in the evaluation of the physical status of the patient. Tolerability and adverse effects were assessed weekly during the treatment period through direct contact (email or telephone) with the patients or their parents.

Quality of life (QOL) assessment was performed using the Short Form-36 (SF-36) health survey questionnaire before starting the treatment and after the fourth week. The questionnaire measures (A) symptomatology; (B) health status before starting the treatment defined as (i) excellent; (ii) good; (iii) liable; (iv) shoddy; (C) general health status after the treatment defined as (i) better than before; (ii) more or less the same as before; (iii) worse than before. The percentage scores range from $0 \%$ (lowest or worst response) to $100 \%$ (highest or best possible response) ${ }^{18}$. Benefits declared by patients were also reported after the treatment in addition to some subjective observations related to the symptomatology and to the health status. Adverse reactions presented during the treatment were also declared.

Statistical analysis. The statistical analysis was performed using the Mann-Whitney test (continuous variables not normally distributed) and the chi-squared test (categorical variables). Statistical significance was set at a $\mathrm{P}$ value $<$ 0.05 , and all data were analysed using the $\mathrm{R}$ software, version 3.1.2.

\section{RESULTS}

Patients. Fifty patients [ 28 women (56\%) and 22 men (44\%), aged between 40 and 85 years old (mean age 64 years old)] were treated with overwintered-stressed Chondrus Crispus dietary supplementation and 30 patients $[15$ women $(50 \%)$ and 15 men (50\%), aged between 40 and 83 years old (mean age 65 years old)] were treated with the non-overwinteredstressed Chondrus crispus dietary supplementation formula.

(A) Results of SF-36 symptomatology of both the treated group are summarized in Table 2.

(B) Results of SF-36 health status before starting the treatment with overwintered-stressed Chondrus Crispus demonstrated that 38 patients $(76 \%)$ had a liable health and 12 patients (24\%) had a shoddy health. Results of SF-36 health status before starting the treatment of the non-overwintered-stressed Chondrus crispus group demonstrated that 21 patients $(70 \%)$ had a liable health and 9 patients $(30 \%)$ had a shoddy health. Anyone declared to have excellent or good health.

(C) Results of SF-36 general health status after the treatment with overwintered-stressed Chondrus Crispus demonstrated that 37 patients $(74 \%)$ felt better than before and 31 patients $(26 \%)$ felt unchanged. Results of SF-36 general health status after the treatment of the non-overwintered-stressed Chondrus crispus group demonstrated that 11 patients $(36.7 \%)$ felt better than before and 19 patients $(63.3 \%)$ felt more or less the same as before. Anyone declared to felt a worse health than before $(\mathrm{P}<0.01)$.

Thirty eight patients $(76 \%)$ treated with overwinteredstressed Chondrus Crispus declared to have benefits to the treatment and 12 patients (24\%) did not report any relief. Of the non-overewintered-stressed Chondrus crispus group, 10 patients $(33.3 \%)$ declared to have benefits to the treatment and 20 patients $(66.7 \%)$ did not report any relief $(\mathrm{P}<0.01)$.

Subjective observations related to the symptomatology declared by patients after the treatment are summarized in Table 3.

Subjective observations about health status declared by patients after the treatment are summarized in Table 4.

Five patients $(10 \%)$ treated with overwintered-stressed Chondrus Crispus referred adverse reactions to the treatment (3 patients had diarrhoea and 2 patients had constipation), so the dosage was reduced to 2 capsules/day. The treatment was well tolerated at the dosage of 3 capsules/day in $90 \%$ of patients. Of the non-overwintered-stressed Chondrus crispus group, any patients referred adverse reactions to the treatment that was well tolerated at the dosage of 3 capsules/day in 100\% of patients. Any other adverse reaction was observed in both the groups.

Muscle energy recovery of subjects treated with overwintered-stressed Chondrus Crispus was higher (84\%, 42/50 patients; Table 4) than in the group treated with non-overwintered-stressed Chondrus crispus (33.3\%, 10/30 patients; Table 4), as shown the request of the 


\begin{tabular}{|c|c|c|c|c|c|}
\hline Parameter & Unit & $\begin{array}{l}\text { Non-overwintered-stressed } \\
\text { chondrus crispus }\end{array}$ & $\begin{array}{l}\text { Overwintered-stressed } \\
\text { chondrus } \\
\text { crispus (2014) }\end{array}$ & $\begin{array}{l}\text { Overwintered-stressed } \\
\text { chondrus } \\
\text { crispus (2015) }\end{array}$ & $\begin{array}{l}\text { Overwintered-stressed } \\
\text { chondrus crispus } \\
(2017)\end{array}$ \\
\hline Citrulline & $\mathrm{g} / \mathrm{kg}$ & 2.81 & 5.16 & 4.69 & 3.33 \\
\hline Tryptophan & $g / 100$ & 0.174 & 0.203 & 0.195 & 0.196 \\
\hline Hydroxyproline & $g / 100$ & $<0.05$ & $<0.05$ & $<0.05$ & $<0.05$ \\
\hline Ornithine & $g / 100$ & 0.178 & 0.889 & 0.532 & 0.526 \\
\hline Threonine & $\mathrm{g} / 100$ & 0.684 & 0.802 & 0.706 & 0.744 \\
\hline Aspartic acid & $g / 100$ & 1.47 & 1.81 & 1.52 & 1.63 \\
\hline Serine & $g / 100$ & 0.802 & 0.908 & 0.756 & 0.814 \\
\hline Lysine & $g / 100$ & 0.787 & 1.05 & 0.882 & 0.896 \\
\hline Valine & $g / 100$ & 0.795 & 0.996 & 0.872 & 0.881 \\
\hline Proline & $\mathrm{g} / 100$ & 0.669 & 1.2 & 0.961 & 1.00 \\
\hline Alanine & $g / 100$ & 0.957 & 1.15 & 1.02 & 1.07 \\
\hline Phenylalanine & $\mathrm{g} / 100$ & 0.658 & 0.877 & 0.813 & 0.820 \\
\hline Isoleucine & $g / 100$ & 0.652 & 0.778 & 0.692 & 0.696 \\
\hline Glycine & $\mathrm{g} / 100$ & 0.789 & 0.99 & 0.845 & 0.900 \\
\hline Thirosine & $g / 100$ & 0.466 & 0.561 & 0.475 & 0.564 \\
\hline Arginine & $g / 100$ & 1.02 & 3.83 & 2.48 & 2.52 \\
\hline Leucine & $\mathrm{g} / 100$ & 1.05 & 1.27 & 1.12 & 1.20 \\
\hline Histidine & $g / 100$ & 0.200 & 0.263 & 0.234 & 0.253 \\
\hline Glutamic acid & $\mathrm{g} / 100$ & 1.85 & 3.06 & 2.21 & 2.24 \\
\hline Methionine & $\mathrm{g} / 100$ & 0.290 & 0.342 & 0.321 & 0.324 \\
\hline Cysteine & $\mathrm{g} / 100$ & 0.249 & 0.341 & 0.271 & 0.274 \\
\hline Taurine & $\mathrm{mg} / 100$ & 333 & 319 & 452 & 468 \\
\hline L-citrullynin-L-arginine & $\mathrm{g} / 100$ & 0.2 & 4.1 & 2.8 & 3.0 \\
\hline Azote & $g / 100$ & 2.96 & 5.27 & 3.81 & 3.92 \\
\hline Proteins & $g / 100$ & 18.5 & 32.9 & 23.8 & 24.5 \\
\hline Sugars & $g / 100$ & 2.9 & $<0.1$ & $<0.1$ & $<0.1$ \\
\hline Fats & $g / 100$ & 0.6 & 0.6 & 1.0 & 1.2 \\
\hline Minerals & $g / 100$ & 25.47 & 21.91 & 24.07 & 23.58 \\
\hline Sodium & $g / 100$ & 4.4 & 3.3 & 4.1 & 3.982 \\
\hline
\end{tabular}

Table 2: Symptomatology declared by patients before starting the treatment assessed by the SF-36
questionnaire. Results are expressed in terms of symptoms' frequency

same patients to follow-up with the dietary supplement administration at the end of the first bottle due to the observed and subjective clinical benefits, while patients treated with non-overwintered-stressed Chondrus crispus did not require to repeat the treatment.

The best treatment responders were people complaining of musculoskeletal and articular pain, due to articular and cartilaginous causes (with arthrosis, arthritis, lumbar pain on a slipped disc basis). They declared satisfactory fitness recovery and joint mobility at the end of the treatment.

The energetic benefit was also observed in patients with cancer undergoing chemotherapy and radiotherapy with overwintered-stressed Chondrus Crispus dietary supplementation.

A further benefit observed in at least $30 \%$ of patients taking overwintered-stressed Chondrus Crispus said they

Asian Journal of Medical Sciences | Nov-Dec 2018 | Vol 9 | Issue 6 


\begin{tabular}{|c|c|c|}
\hline \multirow[t]{2}{*}{ Subjective observations about symptoms } & \multicolumn{2}{|c|}{ Frequency } \\
\hline & $\begin{array}{l}\text { Overwintered-stressed chondrus } \\
\text { crispus group }(\mathrm{N}=50)\end{array}$ & $\begin{array}{c}\text { Non-overwintered-stressed chondrus } \\
\text { crispus group }(\mathrm{N}=30)\end{array}$ \\
\hline Less exhaustion & 19 & 5 \\
\hline Less fatigue & 17 & 6 \\
\hline Mood improvement & 13 & 1 \\
\hline Less pain & 5 & 0 \\
\hline Mild improvement of the symptoms & 5 & 3 \\
\hline Concentration improvement & 2 & 0 \\
\hline Digestive and peristalsis disturbances improvement & 3 & 0 \\
\hline No effects & 9 & 21 \\
\hline
\end{tabular}

\begin{tabular}{|c|c|c|}
\hline \multirow{2}{*}{$\begin{array}{l}\text { Subjective observations about health } \\
\text { status }\end{array}$} & \multicolumn{2}{|c|}{ Frequency } \\
\hline & $\begin{array}{l}\text { Overwintered-stressed chondrus } \\
\text { crispus }(\mathrm{N}=50)\end{array}$ & $\begin{array}{c}\text { Non-overwintered-stressed chondrus } \\
\text { crispus group }(\mathrm{N}=30)\end{array}$ \\
\hline More strength and energy & 42 & 10 \\
\hline Persistent asthenia and/or fatigue & 10 & 15 \\
\hline $\begin{array}{l}\text { Symptoms persistence but the patients felt } \\
\text { better before starting the treatment }\end{array}$ & 10 & 4 \\
\hline Improvement of serenity & 10 & 1 \\
\hline Absence of symptoms & 3 & 1 \\
\hline
\end{tabular}

had benefits on the normalization of intestinal peristalsis and on digestive functions (patients suffering from colitis, 3/8 patients (Table 3-4).

In conclusion, as assessed before, the general benefit improvement of overwintered-stressed Chondrus Crispus administration was $76 \%$, while that obtained with nonoverwintered-stressed Chondrus crispus was 33.3\% ( $<<0.01)$

\section{DISCUSSION}

This retrospective observational "not inferiority" study evidences that overwintered-stressed Chondrus Crispus dietary supplementation improved musculoskeletal and articular symptoms with underlying inflammatory and degenerative background better than non-overwintered-stressed Chondrus crispus, with very mild side effects. Specifically, it has been observed a great improvement of exhaustion, fatigue, pain, digestive, and peristalsis disturbances symptoms, in addition to mood and mental concentration amelioration probably as surrogate endpoints of symptoms. Comparatively, the general benefit of treatment with the overwintered-stressed red seaweed was $76 \%$, while with the one non-overwinteredstressed was 33.3\% ( $\mathrm{P}<0.01)$.

A possible explanation of this different performance is that overwintered exposition of Chondrus crispus naturally enriched the seaweed in a dipeptide, the L- citrullynin-Larginine, compared to other sources of regular Chondrus crispus (Table 1). In addition, this one has a major content in total proteins that makes the dietary supplementation more energizing than the normal seaweed demonstrating the best therapeutic results obtained in patients treated with the overwintered-stressed Chondrus crispus. Seasonal variations in nutritional values of Chondrus crispus are notable, as described in Table 1. Furthermore, previous studies demonstrated seasonal different concentrations in amino acids and in the dipeptide L- citrullynin-L-arginine in Chondrus crispus and in others red seaweeds. ${ }^{19}$ This one has been demonstrated to have in vitro antioxidant activity ${ }^{19}$. Laycock et al. (1980) demonstrated that cold exposure $\left(8^{\circ}\right)$ of Chondrus crispus improved this dipeptide production and it accumulates at this temperature. ${ }^{20}$ This could be due to a direct effect of temperature on the enzyme systems involved in dipeptide metabolism or simply by a result of slower growth. ${ }^{20}$ In fact, the experiments demonstrated that when Chondrus crispus was kept in nitrogen deficient culture at higher temperatures $\left(15^{\circ}\right), \mathrm{L}$ - citrullynin-L-arginine was consumed rapidly, by arginase enzyme that catalyse the hydrolysis of the dipeptide bond between citrulline and arginine. This condition is not verified at lower temperature. In fact, it would be advantageous for the plant to invest the energy needed for uptake and reduction of nitrate and the biosynthesis of nitrogen storage compounds during a time of low temperatures when growth is restricted and there is a surplus of available nitrate. ${ }^{20}$ Generally speaking, dipeptides, has a high nutritional values in terms of energetic contribution because of the break of chemical 
bonds between the two amino acids, releases a stronger energetic power compared to single amino acid content. In fact, commercially available dietary supplementation with the claim to improve strength and energy has a high content of others dipeptide, such as L-carnosine ( $\beta$-alanylL-histidine) to achieve the fine sporting art results due to the buffering activities of carnosine and its related imidazole-containing compounds which contribute to the maintenance of the acid-base balance in the acting muscles. ${ }^{21}$

A recent study demonstrated that a further red seaweed that coexisted with Chondrus crispus, e.g., Mostocarpus stellatus, has a greater freezing tolerance when compared with Chondrus crispus due to its definite proline content storage after cold exposure. ${ }^{22}$ In this study, a range of molecular mechanism have been proposed for cryprotectants, including detoxifying radical oxygen species (ROS), scavenger with the function of compatible osmolytes, and replacing water in the stabilization of membrane and protein conformation. ${ }^{22}$ With regard to membrane integrity, cryoprotectants such as proline interact with membrane surfaces to limit damaging phospholipid phase changes or membrane fusion during freezing-induced cell collapse. ${ }^{23,24}$

Clinical conditions with significantly depleted amino acid levels have, such as cancer, infections, sarcopenia, colitis, rheumatologic, trauma, musculoskeletal, articular, autoimmune and genetic diseases have been associated with long-term fatigue due to negative nitrogen balance in the energetic metabolism. ${ }^{14}$ This can be due to inadequate amino acids availability because of insufficient protein intake or impaired digestion. The amino acids requirement is balanced by proteolysis of non-myofibrillar muscle proteins. A prolonged state of negative nitrogen balance could result in further proteolysis of myofibrillar proteins, with subsequent muscle wasting and damage. Increased metabolic activities to support exercise, mount host defences against infection, or support recovery from illness and injury, place additional demands on protein turnover within the body. ${ }^{9,10,25}$ If a net negative nitrogen balance is associated with fatigue then it would follow that amino acid supplementation would have the potential to assist in restoring nitrogen balance. ${ }^{26}$

The benefits of overwintered-stressed Chondrus Crispus might also depends on the higher total proteins concentrations compared to the non-stressed red seaweed (from $23.8 \mathrm{~g} / 100$ to $32.9 \mathrm{~g} / 100$ and $18.5 \mathrm{~g} / 100$ respectively and amino acids content as especially arginine and citrulline (Table 1).

In conclusion, overwintered-stressed Chondrus Crispus supplementation displayed most energizing properties than the non-stressed red seaweed dietary supplementation because of a huge content in amino acids and total proteins supplying deficiency.

\section{* BIO-ARCT ${ }^{\circledR}$ (Iontec, Monaco)}

\section{Conflict of interest statement}

The authors certify that there is no conflict of interest with any financial organization regarding the material discussed in the manuscript.

The authors hereby certify that all work contained in this article is original. The authors claim full responsibility for the contents of the article. The article has been neither published elsewhere nor submitted for publication simultaneously. If accepted, the paper will not be published elsewhere in the same or similar form, in English or in any other language

All the authors contributed equally to this work.

\section{REFERENCES}

1. Liu J, Hafting J, Critchley AT, Banskota AH and Prithiviraj B. Components of the cultivated red seaweed Chondrus crispus enhance the immune response of Caenorhabditis elegans to Pseudomonas aeruginosa through the pmk-1, daf-2/daf-16, and skn-1 pathways. Appl Environ Microbiol 2013; 79(23):7343-7450.

2. Chopin T GT and Davison I. Phosphorus and nitrogen nutrition in Chondrus crispus (Rhodophyta): effects on total phosphorus and nitrogen content, carrageenan production, and photosynthetic pigments and metabolism. J Phycol 1995; 31:10.

3. McCandless EL, Craigie JS and Walter JA. Carrageenans in the gametophytic and sporophytic stages of Chondrus crispus. Planta 1973; 112(3):201-212.

4. Braakhuis AJ and Hopkins WG. Impact of Dietary Antioxidants on Sport Performance: A Review. Sports Med 2015; 45(7):939-955.

5. Boirie Y. Physiopathological mechanism of sarcopenia. J Nutr Health Aging 2009; 13(8):717-723.

6. Jagoe RT and Engelen MP. Muscle wasting and changes in muscle protein metabolism in chronic obstructive pulmonary disease. Eur Respir J Suppl 2003; 46:52s-63s.

7. Udenfriend $S$ and Wyngaarden JB. Precursors of adrenal epinephrine and norepinephrine in vivo. Biochim Biophys Acta 1956; 20(1):48-52.

8. de Koning TJ, Snell K, Duran M, Berger R, Poll-The BT and Surtees R. L-serine in disease and development. Biochem J 2003; 371(Pt 3):653-661.

9. Poortmans JR, Carpentier A, Pereira-Lancha LO and Lancha A. Protein turnover, amino acid requirements and recommendations for athletes and active populations. Braz J Med Biol Res 2012; 45(10):875-890.

10. Phillips SM. Protein requirements and supplementation in strength sports. Nutrition 2004; 20(7-8):689-695.

11. Dunstan RH, Sparkes DL, Dascombe BJ, Macdonald MM, Evans CA and Stevens CJ. Sweat Facilitated Amino Acid Losses in Male Athletes during Exercise at 32-34 degrees C. PLoS One 2016; 11(12):e0167844.

12. Martone AM, Lattanzio F, Abbatecola AM, Carpia DL, Tosato M 
and Marzetti E. Treating sarcopenia in older and oldest old. Curr Pharm Des 2015; 21(13):1715-1722.

13. Wandrag L, Brett SJ, Frost $G$ and Hickson M. Impact of supplementation with amino acids or their metabolites on muscle wasting in patients with critical illness or other muscle wasting illness: a systematic review. J Hum Nutr Diet 2015; 28(4):313-330.

14. Niblett SH, King KE, Dunstan RH, Clifton-Bligh P, Hoskin LA and Roberts TK. Hematologic and urinary excretion anomalies in patients with chronic fatigue syndrome. Exp Biol Med (Maywood) 2007; 232(8):1041-1049.

15. Di Cerbo A and Palmieri B. The economic impact of second opinion in pathology. Saudi Med J 2012; 33(10):1051-1052.

16. Palmieri $B$ and lannitti T. The Web Babel syndrome. Patient Educ Couns 2011; 85(2):331-333.

17. Palmieri B, lannitti T, Capone S, Fistetto $G$ and Arisi E. Second opinion clinic: is the Web Babel Syndrome treatable?. Clin Ter 2011; 162(6):575-583.

18. McHorney CA, Ware JE, Lu JF and Sherbourne CD. The MOS 36-item Short-Form Health Survey (SF-36): III. Tests of data quality, scaling assumptions, and reliability across diverse patient groups. Med Care 1994; 32(1):40-66.

19. Laycock MV, Morgan KC and Craige JS. Physiological factors affecting the accumulation of L-citrullinyl-L-arginine in Chondrus crispus. Can J Bot 1980; 59:6.

20. Laycock MV and Craigie JS. The occurrence and seasonal variation of gigartinine and L-citrullinyl-L-arginine in Chondrus crispus Stackh. Can J Biochem 1977; 55(1):27-30.

21. Babizhayev MA and Yegorov YE. An "enigmatic" L-carnosine (beta-alanyl-L-histidine)? Cell proliferative activity as a fundamental property of a natural dipeptide inherent to traditional antioxidant, anti-aging biological activities: balancing and a hormonally correct agent, novel patented oral therapy dosage formulation for mobility, skeletal muscle power and functional performance, hypothalamic-pituitary- brain relationship in health, aging and stress studies. Recent Pat Drug Deliv Formul 2015; 9(1):1-64.

22. McCarty AT and Sotka EE. Geographic variation in feeding preference of a generalist herbivore: the importance of seaweed chemical defenses. Oecologia 2013; 172(4):1071-1083.

23. Takahashi D, Li B, Nakayama T, Kawamura $Y$ and Uemura M. Plant plasma membrane proteomics for improving cold tolerance. Front Plant Sci 2013; 4:90.

24. Anchordoguy TJ, Rudolph AS, Carpenter JF and Crowe JH: Modes of interaction of cryoprotectants with membrane phospholipids during freezing. Cryobiology 1987; 24(4):324-331.

25. Waterlow JC and Jackson AA. Nutrition and protein turnover in man. Br Med Bull 1981; 37(1):5-10.

26. Dunstan RH, Sparkes DL, Macdonald MM, De Jonge XJ, Dascombe BJ and Gottfries J. Diverse characteristics of the urinary excretion of amino acids in humans and the use of amino acid supplementation to reduce fatigue and sub-health in adults. Nutr J 2017; 16(1):19.

\section{Authors Contribution:}

BP-Concept and design of the study, reviewed the literature, manuscript preparation and critical revision of the manuscript; CL- Concept, collected data and review of literature and helped in preparing first draft of manuscript, critical revision of the manuscript; MV- Concept of study, collected data and review of study.

\section{Work attributed to:}

Department of General Surgery and Surgical Specialities, University of Modena and Reggio Emilia, Second Opinion Medical Network, Modena (MO), Italy.

\section{Orcid ID:}

Prof. Beniamino Palmieri- (10 http://orcid.org/0000-0002-0871-138X

Dr Maria Vadalà- id http://orcid.org/0000-0001-7873-5072

Dr Carmen Laurino- (1) http://orcid.org/0000-0002-3020-2338

Source of Support: Not Applicable., Acknowledgement: None., Conflict of Interest: None declared. 